гильника Ольховский // Месопотамия и Кавказ в эпоху энеолита и бронзового века: сборник статей в честь 90-летия д.и.н., члена-корреспондента РАН Рауфа Магомедовича Мунчаева / отв. ред. Ш.Н. Амиров. М., 2018 (в печати).

23. Бианки А.М., Днепровский К.А. Об одном из вариантов погребального обряда майкопской культуры // Вопросы археологии Адыгеи. Майкоп, 1988. C. $71-85$.

24. Кореневский С.Н., Медникова М.Б., Бочковой В.В. Новые данные о разнообразии погребальных обрядов майкопско-новосвободненской общности // Археология, этнография и антропология Евразии. 2015. Т. 43, № 2. С. 34-42.

25. Museibly N. Some issues on general features of the Leilatepe culture // Археология и этнография Азербайджана. № 1. Баку.: Hazar University, 2016. С. 20.

26. Marro C., Bakhshaliyev V., Ashurov S., Excavations at Ovcular tepesi (Nakhihichivan, Azerbaïdjan). Second preliminary report: 2009-2010 seasons // Anatolia Antiqua. Vol. XIX, 2011. P. 53-100.

\title{
CHILDREN AND TEENAGERS' BURIALS DATED BACK TO THE BEGINNING OF THE COOPER-BRONZE AGE ON THE EXAMPLE OF THE MAIKOP-NOVOSVOBDNENSKOE COMMUNITY
}

\section{(C) 2017}

Korenevskiy Sergey Nikolaevich, doctor of historical sciences, leading researcher of Bronze Age Department Institute of Archaeology of Russian Academy of Sciences (Moscow, Russian Federation)

Abstract. The paper is aimed to discuss the problem of children and teenagers' burials of the MaikopNovosvobdnenskoe community (MNC) located in the Caucasus region. Children's burials of the GalugaevskoSereginskiy, the Dolinsky variants and the Novosvobdnenskaya group are rare, but there are weapons and gold ornaments. This situation suggests transferring a high status of their parents by inheritance to the child. But the Psekupskiy variant reflects other situation. Children's burials in its monuments look like children's cemetery or burials of adults in kurgans and in earth graves. They do not contain weapons, tools or ornaments of copper and gold. It is possible to observe that burials of children are in big vessels. That tradition often depended on the degree of the society development.

Keywords: funeral ceremony; children; catacomb; cromlech; barrow; mound; elite; gold; silver; ranking; jewelry; pendants; prestige; burial; tradition; cult; ceramics; weapons; adze; tools; vessel; ochre; status; costume; culture; sign; labor; leader; option; typology.

УДК 902.904

Статья поступила в редакцию 22.08.2017

\section{КУРГАН ХАЛВАЙ 5 - КОМПЛЕКС СИНТАШТИНСКОЙ КУЛЬТУРЫ ИЗ СЕВЕРНОГО КАЗАХСТАНА}

(C) 2017

\author{
Логвин Андрей Викторович, заведующий археологической лабораторией \\ Шевнина Ирина Викторовна, научный сотрудник археологической лаборатории \\ Костанайский государственный университет (2. Костанай, Республика Казахстан) \\ Колбина Алина Викторовна, научный сотрудник отдела региональной истории \\ Костанайский областной историко-краеведческий музей (г. Костанай, Республика Казахстан)
}

Аннотация. Работа посвящена результатам исследования кургана Халвай 5. Памятник находится на левом берегу Тобольского рукава Каратомарского водохранилища (Северный Казахстан, Костанайская область) в 7 км к северо-востоку от поселка Халвай и в 500 м к северо-востоку от синташтинского кургана Халвай 3. Диаметр кургана 30 м со рвом, высота 0,8 м. Под насыпью кургана зафиксировано пять погребений. Все подкурганные захоронения кургана Халвай 5 относятся к XXI веку до н.э. к синташтинской культуре. Все основные погребения кургана Халвай 5 были ограблены в древности. Ров после захоронения усопших (по крайней мере, на момент ограбления ям) какое-то время не засыпался. Погребальные камеры имеют перекрытие из досок и бревен, стены их облицованы корой и травой, дно также устлано травой и корой. В ходе исследования были выполнены следующие анализы: антропологический, палеозоологический, палеоботанический, дендрохронологический, рентгенофлюоресцентный (РФА), радиоуглеродный. Жертвенный комплекс представлен КРС, МРС и лошадьми. Среди находок, полученных в результате исследования кургана Халвай 5: керамические сосуды, бронзовый топор-тесло, каменные наконечники стрел, абразивы и терочники, зооморфный жертвенник-терочник. В насыпи кургана было исследовано погребение раннесарматского времени. 
Логвин А.В., Шевнина И.В., Колбина А.В.

Курган Халвай 5 - комплекс синташтинской культуры...

07.00.00 - исторические науки и археология

Ключевые слова: курган Халвай 5; курган Халвай 3; Синташта; синташтинские памятники; синташтинский погребальный обряд; ограбление могил; эпоха бронзы; Тургай; Тургайский прогиб; эпоха бронзы Тургая; дендрохронология синташтинских памятников; радиоуглеродное датирование синташтинских памятников; рентгенофлюоресцентный анализ синташтинских металлических изделий.

В статье в научный оборот вводятся данные, полученные при исследовании кургана Халвай 5. Памятник расположен на левом берегу Тобольского рукава Каратомарского водохранилища (Северный Казахстан, Костанайская область) в 7 км к северо-востоку от поселка Халвай и в 500 м к северо-востоку от синташтинского кургана Халвай 3 [1-3]. Диаметр кургана 30 м со рвом, высота 0,8 м. Предварительные исследования кургана были ранее опубликованы [4; 5].

В насыпи кургана прослежена следующая стратиграфия: дерн; ниже слой суглинка пестрого цвета с преобладанием оранжевых включений (рис. 1), в нем же фиксируются линза супеси зеленого цвета, прослойка супеси серовато-зеленого цвета; ниже погребенная почва - супесь темно-серого цвета; подстилает погребенную почву материковый песок зеленого цвета. Под насыпью кургана зафиксировано четыре погребения (ямы №№ 1, 2, 4, 5), ямы №№ 1, 4 являются центральными погребениями. Одно погребение (яма № 3) является впускным.
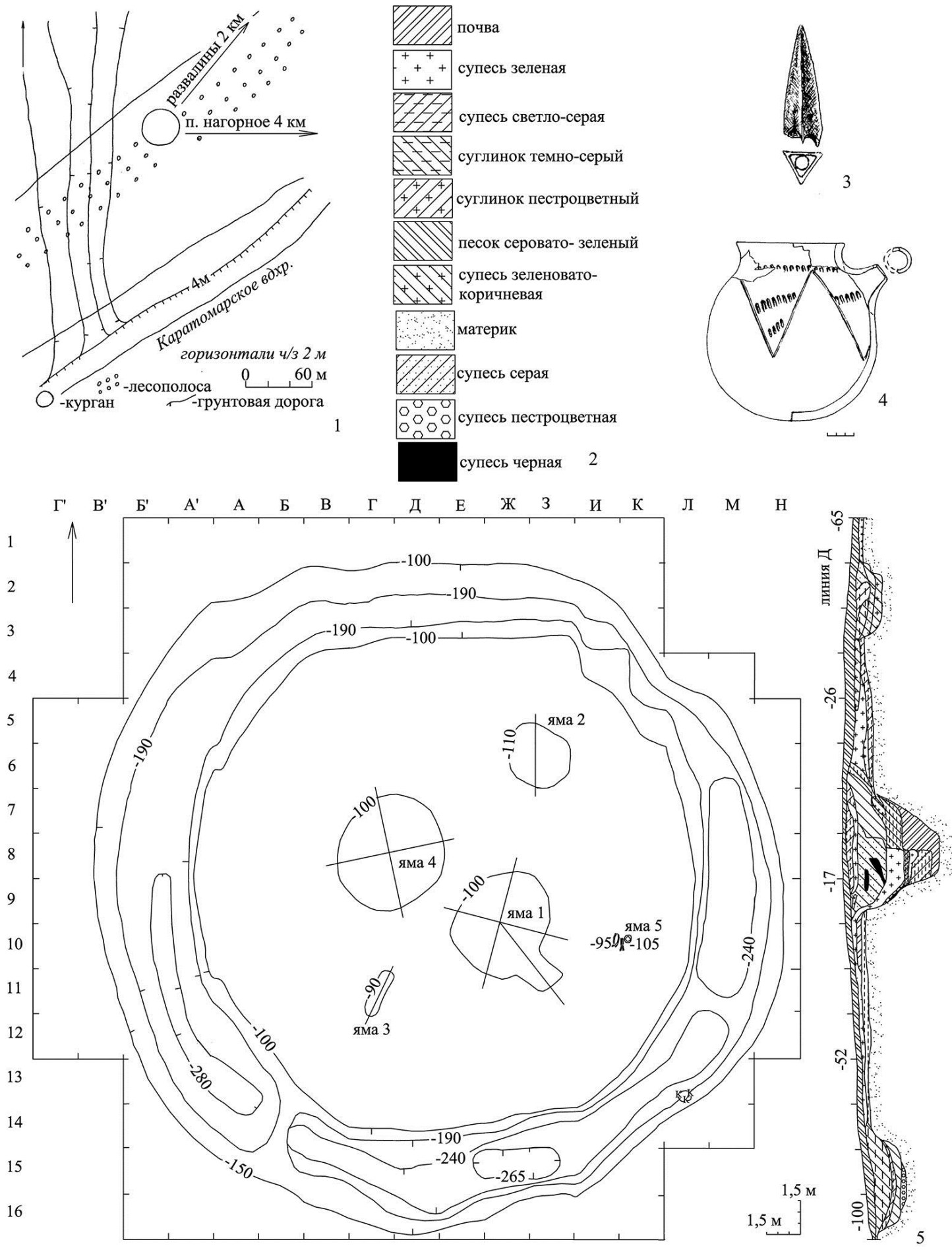

Рисунок 1 - Курган Халвай 5. 1 - ситуационный план; 2- условные обозначения;

3- бронзовый наконечник стрелы из ямы № 3; 4- керамический сосуд из ямы № 3; 5- план раскопа 
Логвин А.В., Шевнина И.В., Колбина А.В.

07.00.00 - исторические науки и археология

Яма № 1 расположена в центральной части кургана (рис. 1). После зачистки яма выглядела как пятно почти круглой формы, с небольшим прямоугольным выступом в юго-западной части. Размеры выступа 1,5×1,3 м, глубина 0,8 м. Размеры ямы 4,1×4,4 м. Глубина ямы 3,1 м. Основное заполнение пятна - супесь серовато-зеленого цвета, по периметру имеется кантик супеси зеленого цвета. Вокруг ямы были расположены черепа животных: один череп барана, три черепа лошадей, четыре черепа КРС и один череп теленка (палеозоологические и ботанические определения выполнены Л.Л. Гайдученко). На глубине 2,7 м размеры ямы уменьшаются $(3 \times 2,3$ м) и она приобретает прямоугольную форму с закругленными углами. Ориентирована яма по линии С-Ю. Начиная с глубины 1,7 м, в северной, западной и частично южной стенке могильной ямы было зафиксировано перекрытие из досок (рис. 4: 3, б). Доски перекрытия были уложены в два ряда. Первый ряд досок был уложен вдоль ямы, второй ряд досок поперек ямы, на первый. При этом доски опирались на края ямы. На досках перекрытия был зафиксирован слой травы с листьями злаков. Некоторые доски перекрытия имеют следы деревообрабатывающих инструментов, которые, скорее всего, происходят от бронзовых топоров-тесел (рис. 4: 8). Стены сохранившейся части погребальной камеры были облицованы вертикально вкопанными досками, обложенными травой и корой (рис. 4: 4, 5). Дно ямы также было устлано корой и травой. C самого верхнего уровня в заполнении ямы начали фиксироваться кости человека и фрагменты керамики. В «выступе-ступеньке» также были найдены кости человека, обломки костей лошади, КРС и овцы. Основные находки зафиксированы на глубине 0,9-2,9 м. Это два черепа лошади, фрагменты керамики, один целый сосуд (рис. 2: 8) и человеческие останки. Фрагменты от второго реконструированного сосуда (рис. 2: 5) были обнаружены как в самой яме, так и на дне рва $(2,8$ м). Кроме этого, на площади раскопа были найдены фрагменты керамики от сосудов, части которых находились в заполнении ямы № 1 .

По антропологическим определениям в яме находились останки четырех человек - двух мужчин возрастом 25-30 и 20-25 лет и двух женщин возрастом 30-35 и 18-20 лет (антропологические определения выполнены А.В. Колбиной). В результате реставрации был полностью восстановлен череп мужчины, умершего в молодом возрасте (25-30 лет) (рис. 4: 1, 2). Нижняя челюсть отсутствует. Череп с очень большим продольным и поперечным диаметрами мозговой коробки, по указателю мезокранный. Лоб среднеширокий, наклонный, с хорошо развитым надпереносьем. Затылочная кость очень широкая, со слабо выраженным бугром. Лицо очень широкое, высокое, хорошо профилированное на верхнем уровне. Орбиты низкие и очень широкие. Нос сильно выступающий, с высоким переносьем, очень широкий, гиперхамеринный по указателю. Нижний край грушевидного отверстия со слабо выраженными предносовыми ямками. Описательная характеристика и визуальное восприятие черепа характеризуют его как европеоидный, хотя такие признаки, как крупный череп,
Курган Халвай 5 - комплекс синташтинской культуры. .

высокое и широкое лицо наблюдаются в монголоидных сериях. Зубы не имеют выраженных расовых диагностических признаков. На резцах и клыках отмечена эмалевая гипоплазия в виде горизонтальных полосок, как следствие дефицита питания (недостаток кальция) в период формирования постоянных зубов. На сосцевидных отростках наблюдаются патологические изменения костной ткани (мастоидит), вызванный хроническим процессом воспаления среднего уха.

Погребальный инвентарь представлен только керамическими изделиями. Оба сосуда имеют плавную профилировку. Шейка одного сосуда отогнута и имеет небольшой налепной валик, другой сосуд имеет внутреннее ребро на шейке и налепные «шишечки». Украшены сосуды «елочкой», каннелюрами, ромбами, треугольниками, полукружиями и линиями. Орнамент наносился вдавлениями, зубчатым штампом, прочерчиванием и резной техникой. Тесто с примесью талька.

Яма № 2 расположена в северо-восточном секторе кургана, к северу от ямы № 1 (рис. 1). После зачистки яма выглядела как пятно почти круглой формы. Размеры ямы 2,65×2,6 м. Глубина 1,8 м. Основное заполнение пятна - супесь серовато-зеленого цвета. На глубине 0,5 м размеры ямы уменьшаются и она приобретает прямоугольную форму с закругленными углами. Ориентирована яма по линии С-Ю. В заполнении ямы фиксировались кости молодого козла и лошади, фрагменты керамики (13 фр.) (рис. 2: б). На глубине 1,5 м в восточной части ямы зафиксирован древесный тлен по контуру стенок ямы, видимо, это остатки перекрытия. По всей видимости, и эта яма была также ограблена в древности.

Яма № 4 расположена в центральной части кургана, к западу от ямы № 1 (рис. 1). После зачистки яма выглядела как пятно округлой формы. Размеры ямы $5 \times 4,8$ м. Глубина 3,3 м. Заполнение пятна неоднородное. По периметру ямы фиксируется кантик серовато-зеленого цвета. Ближе к южной стенке ямы отмечено пятно черного цвета со скоплениями углей. Перекрытие ямы не обнаружено. С глубины 2,5 м вдоль восточной стенки прослеживается тлен и прослойка из стеблей и листьев злаков. На краю ямы у южной стенки зафиксирован череп лошади. На глубине 3,2 м размеры ямы уменьшаются и она приобретает прямоугольную форму с закругленными углами. С глубины 0,2 м и до дна ямы были обнаружены следующие находки: разрозненные кости человека (они принадлежали женщине 30-40 лет), лошадей и овец, каменные наконечники, бронзовый топортесло, обломок гальки, зооморфный каменный жертвенник-терочник (рис. 4, 7). Кроме этого, фрагменты от одного сосуда найдены в заполнении ямы № 4 и на площади раскопа, в насыпи на глубине 0,7-1,05 м от уровня современной поверхности.

Погребальный инвентарь. Топор-тесло (рис. 2: 4) с остатками кожаной обмотки и фрагментами деревянной рукояти был изготовлен из мышьяковистой бронзы (рентгенофлуоресиентный анализ (РФА) выполнен И.А. Блиновым, М.Н. Анкушевым, В.В. Зайковымм) (табл. 1).

Таблица 1 - Результаты рентгенофлуоресцентного (РФА) анализа металлических изделий кургана Халвай 5

\begin{tabular}{|l|l|c|c|c|c|c|c|c|c|}
\hline \multirow{2}{*}{ Место находки } & \multirow{2}{*}{ Изделие } & \multicolumn{7}{|c|}{ Содержание, \% } & \multirow{2}{*}{ Сумма } \\
\cline { 3 - 10 } & & $\mathrm{Cu}$ & $\mathrm{Sn}$ & $\mathrm{As}$ & $\mathrm{Pb}$ & $\mathrm{Ag}$ & $\mathrm{Fe}$ & $\mathrm{Bi}$ & \\
\hline Яма № 4 & Топор-тесло & 84,0 & - & 8,0 & - & - & 1,7 & - & 93,7 \\
\hline Яма № 3 (?) & Наконечник & 99,6 & - & - & - & - & 0,4 & - & 100,0 \\
\hline
\end{tabular}



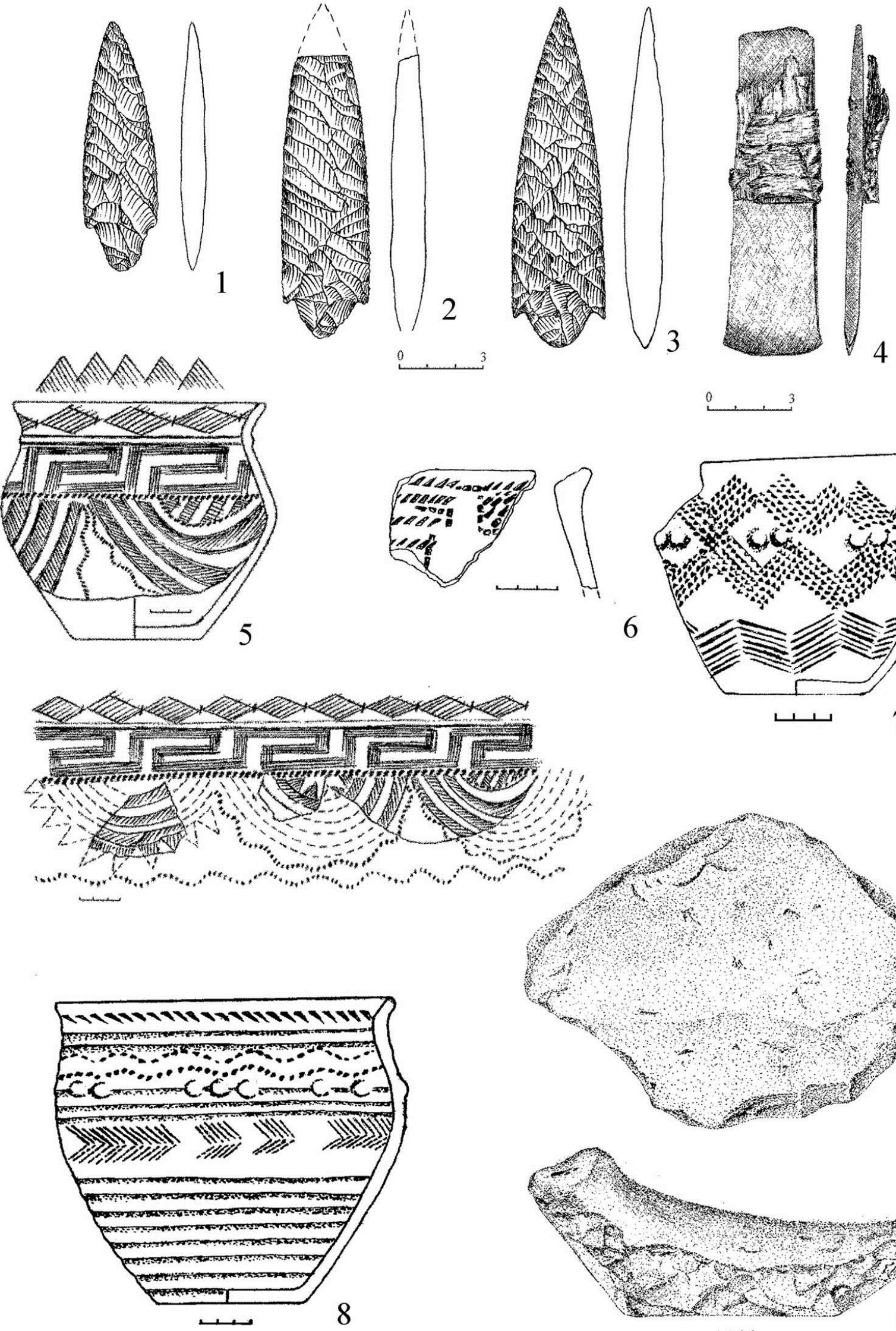

5

6

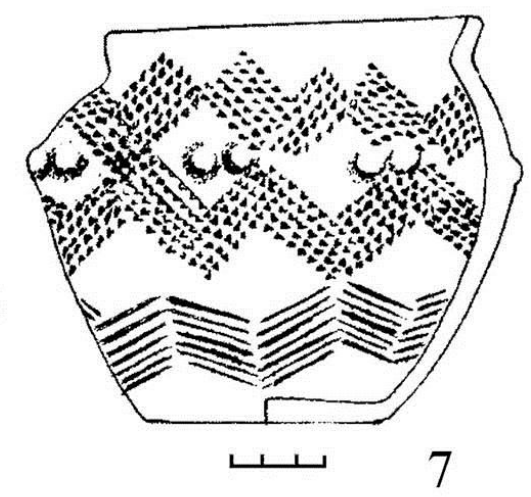

Рисунок 2 - Курган Халвай 5 . Погребальный инвентарь. 1-4, 9- яма № 4; 5, 8- яма № $1 ; 6$ - яма № 2;

7- яма № 5. 1-3, 9- камень; 4- бронза; 5-8- керамика

Двусторонне обработанные наконечники (3 экз.), с черешковым основанием изготовлены из кварцита (1 экз.) и кварцитопесчаника (2 экз.) (рис. 2: 1-3).

Жертвенник-терочник серовато-зеленого цвета, ромбической формы с приостренными концами (рис. 2, 9). Очертания предмета напоминают стилизованное изображение животного. Один край жертвенника оформлен в виде головы животного, выдается вперед, отделен от основной части изделия выемками-сколами, образующими шею зверя. «Голова» 
Логвин А.В., Шевнина И.В., Колбина А.В.

приподнята и сужена, имеет подтреугольную форму. Противолежащий край выделен и закруглен. Обе поверхности зашлифованы, верхняя частично покрыта красной охрой. Размеры изделия: 36×27,3 (наиб. шир.) х 14,3 (толщ.) см. Аналогичный терочник был найден на Мало-Кизыльском селище абашевской культуры [6, с. 39, 70].

Яма № 5 не имеет контура, расположена в юговосточном секторе кургана, восточнее ямы № 1 (рис. 1). На глубине 0,95-1,05 м были зафиксированы череп и кости овцы, керамический сосуд. Человеческие останки не обнаружены. Можно предположить, что яма представляет собой жертвенный комплекс или же яма могла являться погребением ребенка, чей костяк не сохранился.

Сосуд плавной профилировки имеет внутреннее ребро на шейке и налепные «шишечки» по тулову (рис. 2: 5). Орнаментирован ромбами, наклонными колонками оттисков зубчатого штампа и прочерченным многорядным зигзагом. Тесто с примесью талька и шамота.

В заключении описания подкурганных захоронений отметим, что в насыпи кургана зафиксированы кости людей, животных (двух особей собак, кости и черепа лошадей, овцы, и КРС). Кроме этого, на площади раскопа были найдены фрагменты керамики и обломок каменного двусторонне обработанного наконечника.

Ширина раскопанной части рва колеблется от 2 до 4,5 м, глубина достигает 2,8 м. В юго-западном секторе рва на глубине 1 м фиксируется возвышение во рву, шириной до 1,5 м. Возможно, это был вход, соединяющий пространство за пределами кургана с подкурганной площадкой. В южной части рва были зафиксированы челюсти лошадей. В северной части рва зафиксированы череп и челюсти трех особей КРС, череп и челюсти двух лошадей и двух собак. Кроме того, во рву были найдены фрагменты керамики, четыре сосуда, абразив, терочник и каменные наконечники (рис. 3).

Bсе сосуды имеют внутреннее ребро на шейке. Три сосуда плавной профилировки. У одного в месте перехода шейки в тулово имеется сглаженное ребро. Орнаментированы сосуды многорядовым зигзагом,
Курган Халвай 5 - комплекс синташтинской культуры...

треугольниками, полукружиями, каннелюрами и линиями. Техника нанесения орнамента: зубчатый штамп, вдавления, резная техника, прочерчивание, гладкий штамп. Тесто плотное, с примесью талька у всех сосудов.

Двусторонне обработанные черешковые наконечники с «шипами» (3 экз.), изготовленные из серого кварцитопесчаника «струйчатой» ретушью.

В насыпи кургана в юго-западном секторе расположена яма № 3 (рис. 1). После зачистки яма выглядела как пятно овальной формы, ориентированное по линии Ю3-СВ. Размеры ямы $2,1 \times 0,6$ м, глубина 0,15 м. Погребенный 25-30 лет (пол установить не удалось) лежал в вытянутом положении на спине, головой на северо-восток. Руки вытянуты, кисти рук расположены в области таза. Погребального инвентаря нет. Однако следует отметить, что к северу от погребения, в 5-6 м, на глубине 0,3-0,4 м от уровня современной поверхности были обнаружены бронзовый наконечник стрелы и развал сосуда раннесарматского облика. Поверхность кургана была распахана, вследствие чего, вероятно, сосуд и наконечник оказались вне погребения.

Округлодонный сосуд с носиком-сливом. По тулову прочерчиванием нанесены треугольники, заштрихованные рядами овальных вдавлений. Тесто плотное, без видимых примесей.

Наконечник стрелы, трехлопастной со сводчатой головкой и внутренней втулкой, изготовлен из меди (табл. 1).

Полученные результаты дендрохронологического анализа (дендрохронологический анализ древесинь выполнен И.П. Панюшкиной в Лаборатории по изучению годичных колеи деревьев Университета Аризоны (Laboratory of Tree-RingResearch, University of Arizona)) и перекрестного датирования позволяют заключить, что все изученные конструкции курганов Халвай 3 и Халвай 5 были созданы в короткий промежуток времени (1-2 года), а возможно и одновременно. По дереву из перекрытия, для ямы № 1 из кургана Халвай 5 была получена радиокарбонная дата (радиокарбонное датирование на ускорительной масс-спектрометной установке (AMS) было выполнено в Arizona NSFAccelerator facility) [7] (табл. 2).

таблица 2 - Радиоуглеродная дата кургана Халвай 5

\begin{tabular}{|c|c|c|c|c|}
\hline \multirow{2}{*}{ № образца } & Лаб. индекс & ${ }^{14}$ С Возраст BP & \multicolumn{2}{|c|}{ Калиброванный возраст } \\
\cline { 3 - 5 } & & & CalYrs BC 1 $\sigma$ & CalYrs BC 2 $\sigma$ \\
\hline (Н5-33) Курган 5 & АA100937 & $3577+-46$ & $1980-1880 \mathrm{p}=0,86$ & $2040-1860 \mathrm{p}=0,84$ \\
\hline
\end{tabular}

Все погребения кургана Халвай 5 были ограблены в древности. Об этом говорит как сам факт нарушения погребений, так и местонахождение погребального инвентаря. Так, фрагменты от одного сосуда, жертвенный комплекс, разрозненные кости погребенных людей неоднократно фиксировались как в ямах, так и на дне рва и в насыпи. Кроме того, необходимо отметить, что фрагменты от одного сосуда, находящегося в яме № 1 и на дне рва, позволяют с достаточной уверенностью предположить, что ров после захоронения усопших (по крайней мере, на момент ограбления ям) какое-то время не засыпался.
Таким образом, все подкурганные захоронения кургана Халвай 5 относятся к XXI веку до н.э. к синташтинской культуре. Аналогии достаточно широки и связаны, прежде всего, с такими могильниками, как Бестамак [8; 9], Халвай 3 [1-3], Танаберген II [10], Синташта [11], Кривое озеро [12], Каменный Амбар-5 [13], курган 25 Большекараганского могильника [12].

Впускная яма № 3, сосуд с «носиком»и и бронзовый наконечник стрелы, предположительно относящийся к яме № 3, сопоставимы с материалами раннесарматского времени (V-IV вв. до н.э.) [15-18]. 

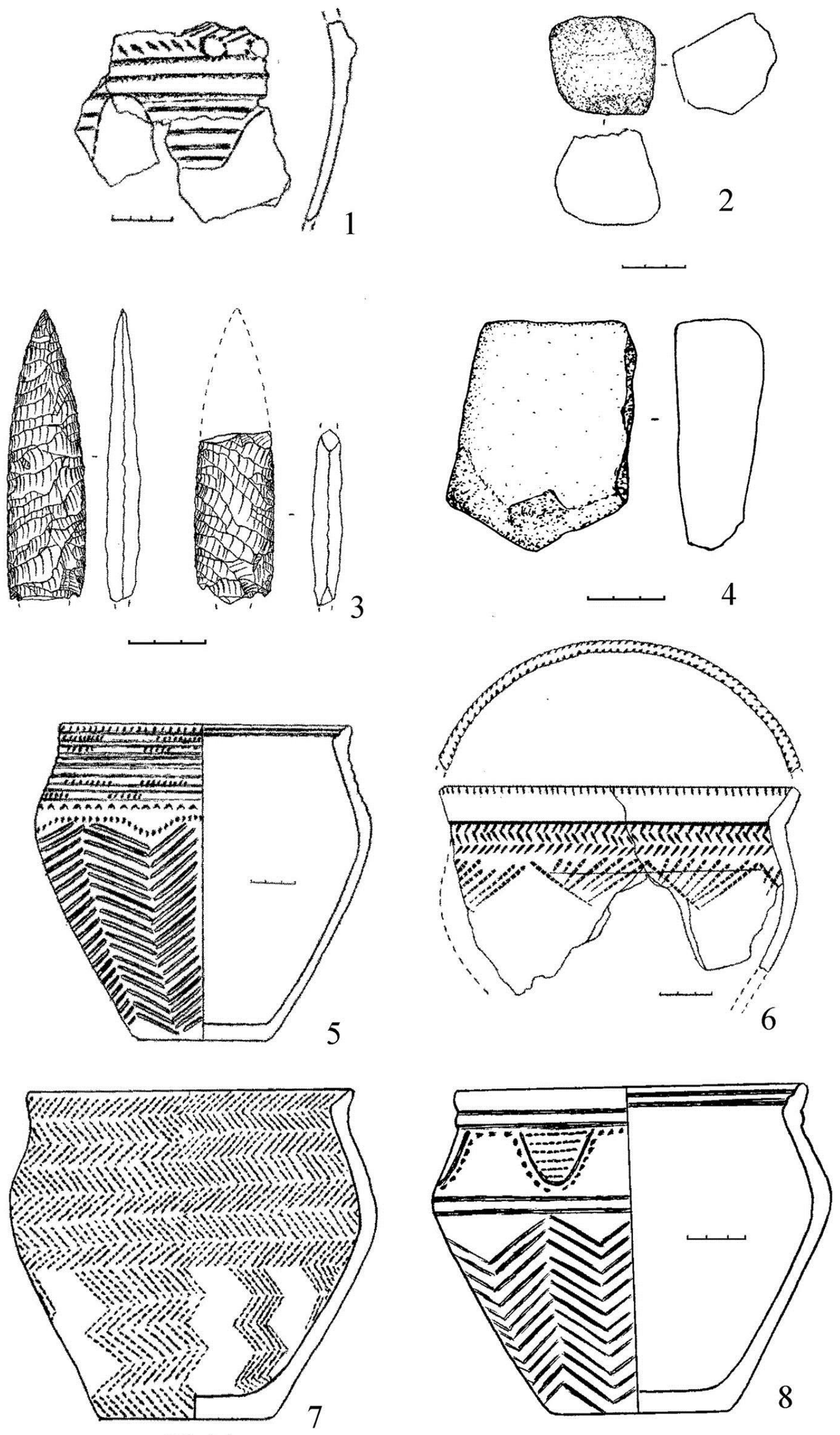

Рисунок 3 - Курган Халвай 5. Погребальный инвентарь из рва. 1, 5-8-керамика; 2-4- камень 

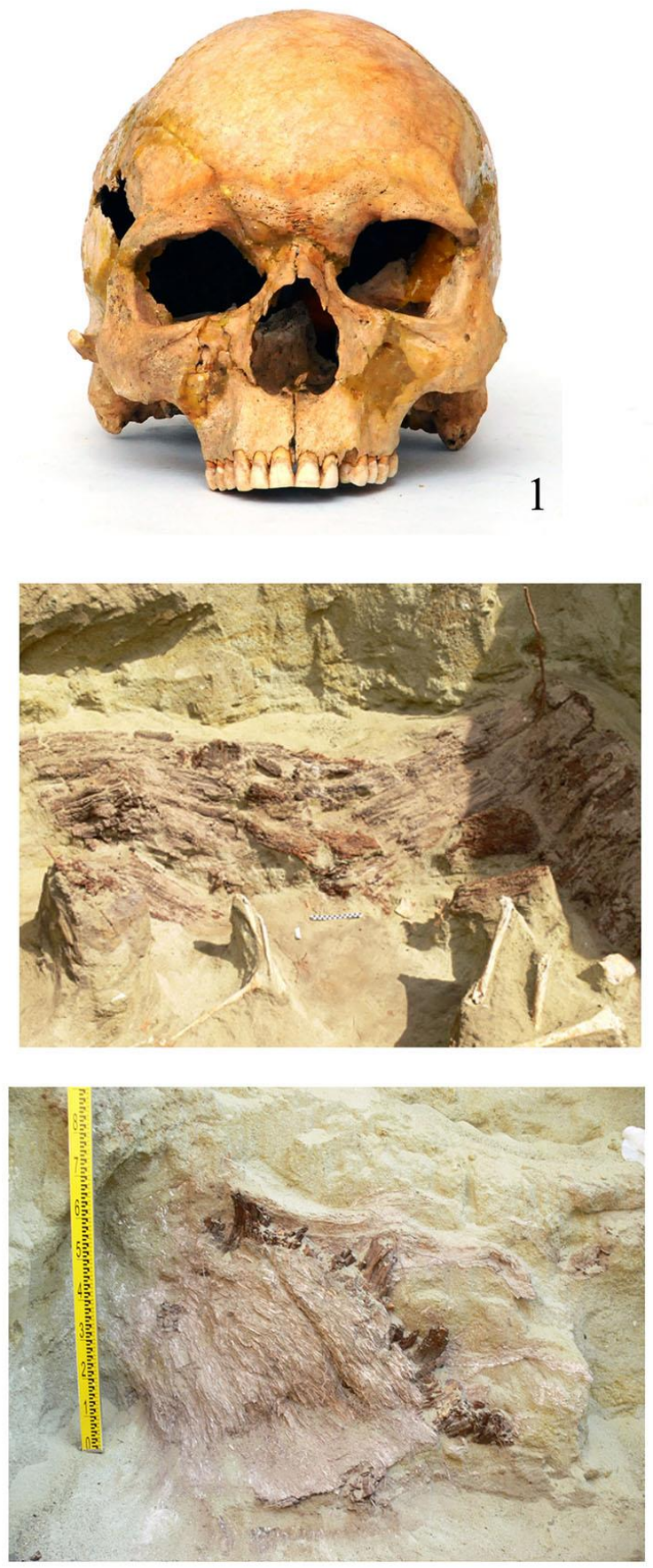

5

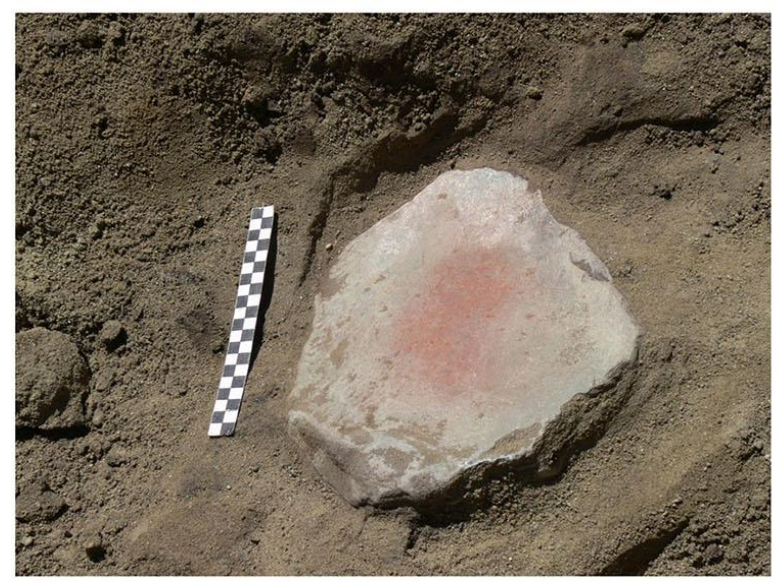

7

3
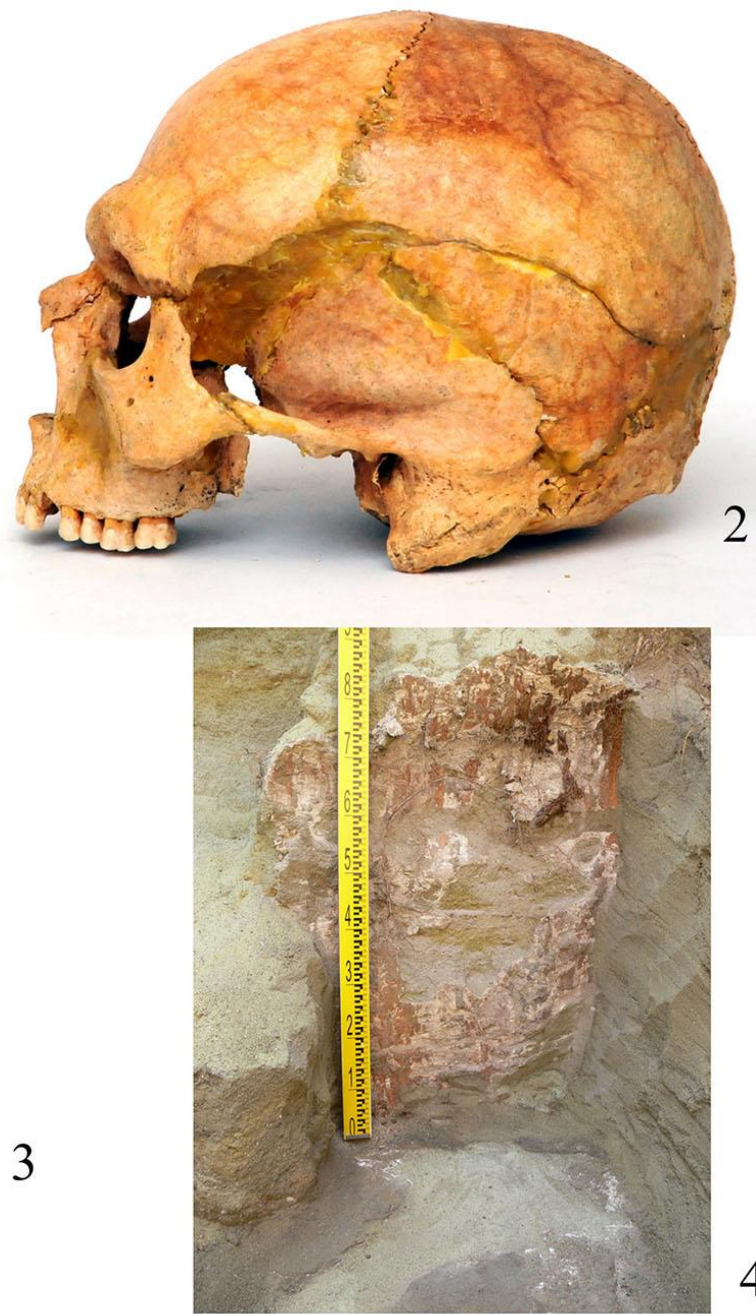

4

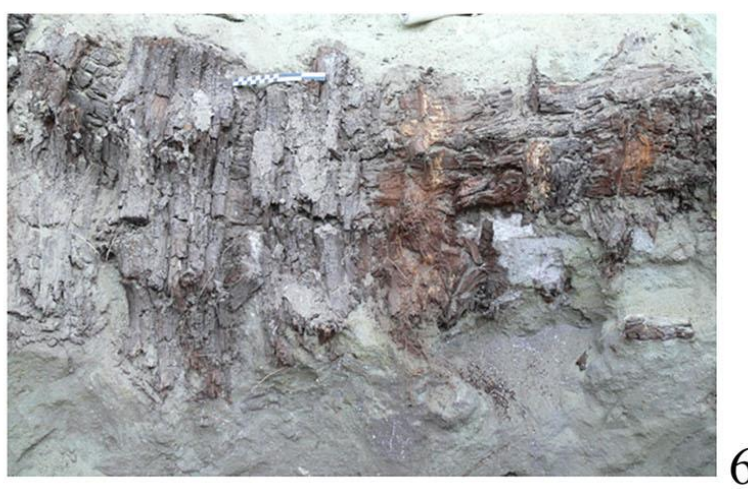

6

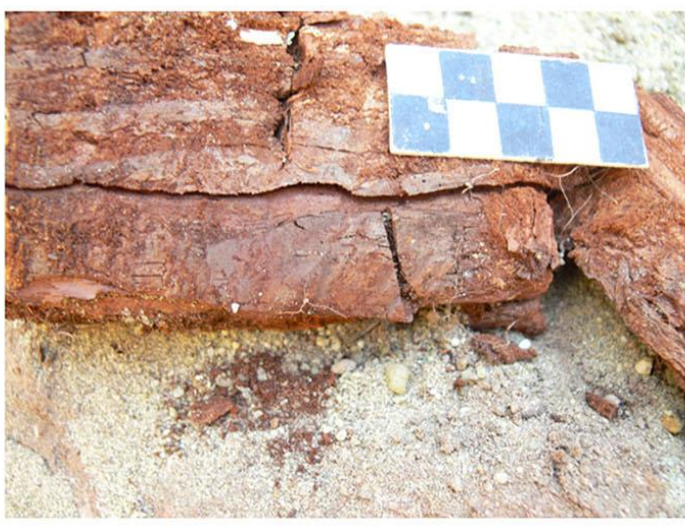

8

Рисунок 4 - Курган Халвай 5. 1, 2- реставрированный череп мужчины 25-30 лет из ямы № 1; 3, 6- остатки перекрытия ямы № 1;

4- фрагмент облицовки стены погребальной камеры корой; 5- слой травы на перекрытии ямы № 1;

7- каменный зооморфный жертвенник-терочник, частично покрытый охрой из ямы № 4;

8 - следы от деревообрабатывающего инструмента на доске из перекрытия из ямы № 1 


\section{СПИСОК ЛИТЕРАТУРЫ:}

1. Логвин А.В., Шевнина И.В. Курган Халвай 3 (предварительное сообщение) // Маргулановские чтения - 2011: материалы международной археологической конференции (20-22 апреля 2011 г., г. Астана). Астана: ЕНУ им. Л.Н. Гумилева, 2011. С. 291296.

2. Шевнина И.В., Логвин А.В. Могильник эпохи бронзы Халвай III в Северном Казахстане // Материалы и исследования по археологии Казахстана. T. VII. Астана: филиал Института археологии им. А.Х. Маргулана, 2015. 248 с.

3. Логвин А.В., Шевнина И.В. Погребения эпохи развитой бронзы кургана Халвай 3 // Prehistory studies. Pontic area. Mangalia: «Callasprint», 2014. C. 219-242.

4. Логвин А.В., Шевнина И.В. Исследования кургана Халвай 5 (предварительное сообщение) // Труды филиала Института археологии им. А.Х. Маргулана. Астана, 2012. Т. 1. С. 38-44.

5. Шевнина И.В., Логвин А.В. Синташтинские курганы в Северном Казахстане (по материалам исследований Халвайских курганов) // Процесс культурогенеза начальной поры позднего бронзового века Волго-Уральского региона (вопросы хронологии, периодизации, историографии): материалы международной научной конференции (12-14 мая 2014 г., г. Самара) / отв. ред. П.Ф. Кузнецов. Самара: ПГСГА, 2014. C. $143-150$.

6. Сальников К.В. Очерки древней истории Южного Урала. М.: Наука, 1967. 407 с.

7. Панюшкина И.П. Календарный возраст курганной группы Халвай // Могильник эпохи бронзы Халвай III в Северном Казахстане / И.В. Шевнина, А.В. Логвин. Астана: Филиал Института археологии им. А.Х. Маргулана, 2015. С. 218-220.

\section{KURGAN HALVAY 5 - A COMPLEX OF SINTASHTA CULTURE FROM NORTHERN KAZAKHSTAN}

(C) 2017

Logvin Andrey Viktorovich, head of Archaeological Laboratory

Shevnina Irina Viktorovna, researcher of Archaeological Laboratory

Kostanay State University (Kostanay, Republic of Kazakhstan)

Kolbina Alina Viktorovna, researcher of Regional History Division

Kostanay Regional Museum of Local History (Kostanay, Republic of Kazakhstan)

Abstract. The paper is devoted to the study results of kurgan Halvay 5, which is located on the left bank of the Tobol branch of the Karatomar Reservoir (Northern Kazakhstan, Kostanay Region) $7 \mathrm{~km}$ to the north-east of Halvay and $500 \mathrm{~m}$ to the north-east of the Sintashta kurgan Halvay 3. The diameter of the kurgan is $30 \mathrm{~m}$ with a moat, the height is $0,8 \mathrm{~m}$. Five burials were recorded under the embankment of the kurgan. All the primary burials of the kurgan Halvay 5 belong to the XXI century BC to Sintashta culture. All the main burials of the kurgan Halvay 5 were robbed in antiquity. The moat after the burial of the deceased (at least at the time of the robbery of the pits) was not filled up for a while. Funerary chambers have an overlapping of boards and logs, their walls are lined with bark and grass, the bottom is also covered with grass and bark. In the course of the study, the following analyses were performed: anthropological, paleozoological, paleobotanical, dendrochronological, X-ray fluorescent (XRF), radiocarbon. The sacrificial complex is represented by cattles, sheeps, and horses. The finds obtained as a result of the study of the kurgan Halvay 5 are: ceramic vessels, a bronze ax-adzo, stone arrowheads, abrasives and a zoomorphic altar. In the kurgan the Early Sarmatian burial was investigated.

Keywords: Kurgan Halvay 5; Kurgan Halvay 3; Sintashta; Sintashta sites; Sintashta funeral rite; grave robbery; Bronze Age; Turgay; Turgay deflection; bronze age of Turgay; dendrochronology of Sintashta sites; radiocarbon dating of Sintashta sites; X-ray fluorescence analysis of Sintashta metal products. 